\title{
Reinforcement of Concretes with Carbon Fiber Composite
}

\author{
Luiz Antônio Melgaço Nunes Branco ${ }^{\mathbf{1}}$, Letícia Couto Aguiar ${ }^{1}$, Eduardo Chahud ${ }^{1}$, \\ Francisco Antonio Rocco Lahr ${ }^{2}$, Tulio Hallak Panzera ${ }^{3}$, André Luis Christoforo, ${ }^{4, *}$ \\ ${ }^{1}$ Faculty of Engineering and Architecture, FUMEC University, Belo Horizonte, 30130-009, Brazil \\ ${ }^{2}$ Department of Structural Engineering, Engineering School of São Carlos (EESC/USP), São Carlos, 13566-590, Brazil \\ ${ }^{3}$ Department of Mechanical Engineering, Federal University of São João del-Rei, São João del-Rei, 36307-352, Brazil \\ ${ }^{4}$ Department of Civil Engineering, Federal University of São Carlos, São Carlos, 13565-905, Brazil
}

\begin{abstract}
The Carbon Fibre Composites (FRP) have long been used to increase the strength of the concrete structures. This happens because they provide a highly effective intervention without changing the geometry of the parts. In Brazil, the concrete are produced for various purposes, and everything depends on the trace set for the basic material constituents. The ability to repair and strengthen concrete structures already designed, this study aimed, with the aid of ABNT NBR 5739 standard and the analysis of variance (ANOVA), assess the strength of concrete in compression with low, medium and high strength (defined by the Brazilian standard) by including laminate carbon fiber composites. From laboratory tests and ANOVA, found efficiency of the reinforcement in all three types of concrete manufactured and greater efficiency in low strength concrete, justified by the lower tensile strength, which means striving responsible for bringing the specimens to failure.
\end{abstract}

Keywords Concrete structures, Structural reinforcement, Carbon fiber

\section{Introduction}

The reinforced concrete structures represent a large portion of the world's buildings. This is due to the excellent combination of properties of concrete and steel that enable the development of highly resistant structures, in various shapes and sizes and with impressive durability [1-4].

It is noteworthy that despite all the technological effort in anticipation of increasing the durability of reinforced concrete, it remains subject to a term of life. Thus, needs periodic maintenance to keep over the years its use conditions defined in the project [5-7].

It happens that, in most cases, is not made the proper conservation of the structure that has just deteriorated to the point of needing reinforcements [8-11].

The study of the causes responsible for the various processes of degradation of concrete structures is indispensable and makes up the complex field of study called Pathology of Buildings [12-15].

The concrete deterioration occurs due to the presence of various aggressive agents in the environment. Although currently there are real high compactness, we know that yet, this material is somewhat permeable and subject to the action of external elements so that when they reach their cause steel

* Corresponding author:

alchristoforo@yahoo.com.br (André Luis Christoforo)

Published online at http://journal.sapub.org/cmaterials

Copyright (C) 2014 Scientific \& Academic Publishing. All Rights Reserved corrosion and consequent deterioration of the structure [16-18], as shown in Figure 1.

In classical structural systems, the pillars play a key role in the structure, since they serve as support and transmit loads to the foundations. Thus, any loss in capacity pillars can result in large and irreversible damage to the structure as a whole, conducting intervention by ribs [8-12] is required.

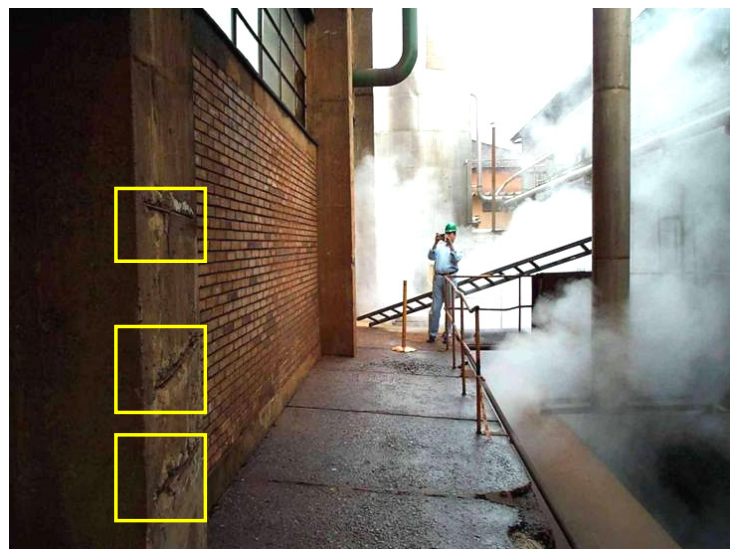

Figure 1. Deterioration of pillars by etching (Brazilian structure)

It is observed that the deterioration of reinforced concrete is not the only occasion on which the recovery of the structure is necessary. In many cases, there is a need to increase due to an increase in the load provided at the time of design, for example, the creation of a library in the building, the increased traffic on a bridge or overpass, and even in cases of claims such as fire and earthquakes [15]. Figure 2 
shows the Viaduct of Santa Teresa in Belo Horizonte (MG-Brazil), which is a work of the early twentieth century and was the first work reinforced with carbon fibers in Brazil, taking into account the need for adequacy of its bearing capacity to current values.
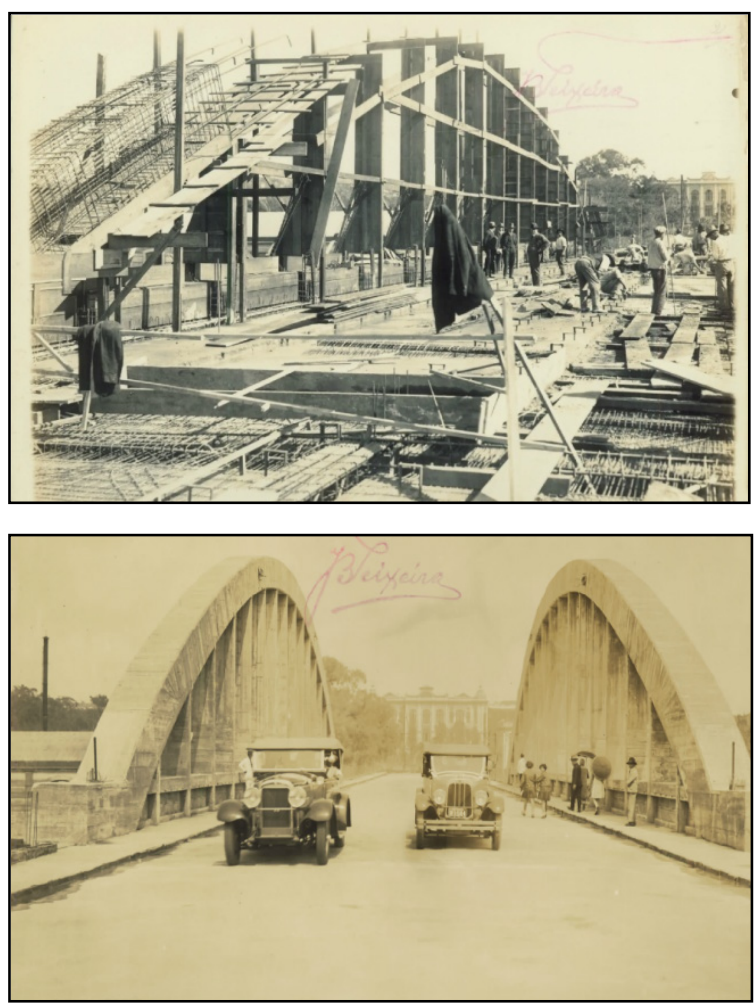

Figure 2. Historical photos of the construction and use of Viaduct Santa Teresa. Source: Public Archives Miner

Currently several different techniques can be used for reinforcement or structural recovery. The methods and techniques of rehabilitation of concrete structures, despite rapid development, are still based on accumulated empirical experience, due to the handmade and unusual character of the rehabilitation processes, since each problem faced has its own characteristics. This is one of the factors leading to the development of research on the structural behavior of rehabilitated reinforced concrete elements [18].

Among the most widely used techniques cites the increase of the pillar section through the casing with new concrete [7, 10]. This technique has good efficiency, but also has some disadvantages such as increased weight of the structure, loss of open area, time consuming and laborious execution.

Another technique is the application of steel plates bonded to concrete with epoxy resin. This is also an effective technique but has drawbacks such as the need for maintenance of the plate, so they do not come in corrosion, increasing the weight on the structure and aesthetic appearance [18].

The more modern technique for the ribs is the use of fiber composites, also called Fibre-Reinforced Polymer (FRP) is a composite made from a polymer matrix reinforced with fibers which may be glass, carbon, etc.
Specifically, the carbon fibers have high mechanical strength and is not subject to various chemical attack or corrosion, thus providing a highly durable material [18]. Additionally, they are extremely lightweight and low thickness, which causes its own weight can be disregarded. The composites can be rigid (as a ruler) or flexible (in fabric form) and its application is extremely rapid, giving the structure a desired strength in a relatively short time depending on the curing time of the epoxy [15]. Thus, application of the carbon fibers does not affect the geometry of the structure, can be used in many different ways.

Considering the advantages of using the booster system with the application of carbon fiber composites, the present research aimed to analyze the behavior of the composite when used to increase the compression strength of concrete columns of circular cross section, with three types of resistance (low, medium and high mechanical strength in compression), enabling investigate its potential application in the form of repair and strengthening of concrete structures manufactured in Brazil.

\section{Material and Methods}

The Brazilian standard ABNT NBR 5738 [19] " Concrete - Procedure for forming and healing of specimen" advocates the use of cylindrical shapes of 10 or $15 \mathrm{~cm}$ in diameter and 20 or $30 \mathrm{~cm}$ height.

However, seeking to bring the samples of the actual structural element tests, specimens were tested in $15 \times 50 \mathrm{~cm}$.

Besides geometry, we intended to verify that influences the strength of concrete to be reinforced in the rate of effectiveness of carbon fiber. Thus, the objective was to examine how the percentage of increase in compression strength of concrete is different in low, medium and high strength.

Carbon fibers are the result of a heat treatment known as carbonization or pyrolysis [14]. By this procedure, oxidation of precursor fibers such as polyacrylonitrile (PAN) and it is processing at temperatures ranging from $1000^{\circ} \mathrm{C}$ to $3000^{\circ} \mathrm{C}$. In this thermal process, the resulting fibers have the carbon atoms perfectly aligned along the fiber, which gives the material high mechanical resistance [15].

For evaluating the efficiency of the carbon fiber factor, six specimens (Cps) of each of the different levels of resistance, low, medium and high were produced, adding eighteen CPs. In each class of resistance, three CPs unreinforced and three other reinforced were tested. All specimens were tested at the age of 28 days, according to [19].

The sequence for reinforcement work consists of the following steps:

A) Manufacture of concrete specimens (Figures 3 and 4):

B) Plastering:

In this step, we seek to fill any voids and imperfections in the concrete. This is to ensure better contact surface for the fibers. In the case of a concrete structure to be repaired must also be carefully predict surface cleaning, since, otherwise 
they run the risk of decreasing the adhesion of the fibers to the substrate, in that the saturating (glue) have contact with the dirt and not the concrete itself.

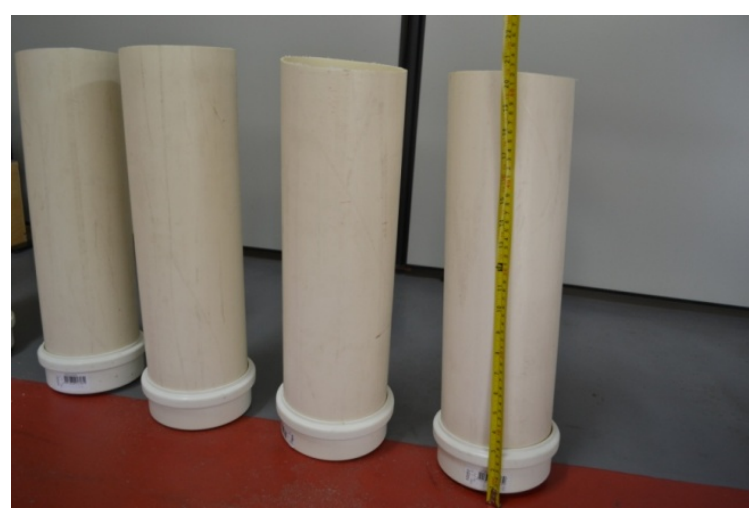

Figure 3. Conference of the height of the shape of the specimens

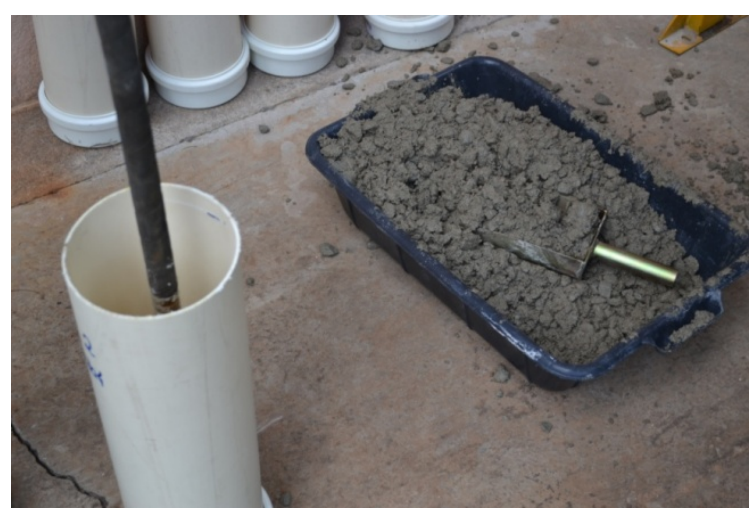

Figure 4. Molding of the test specimens

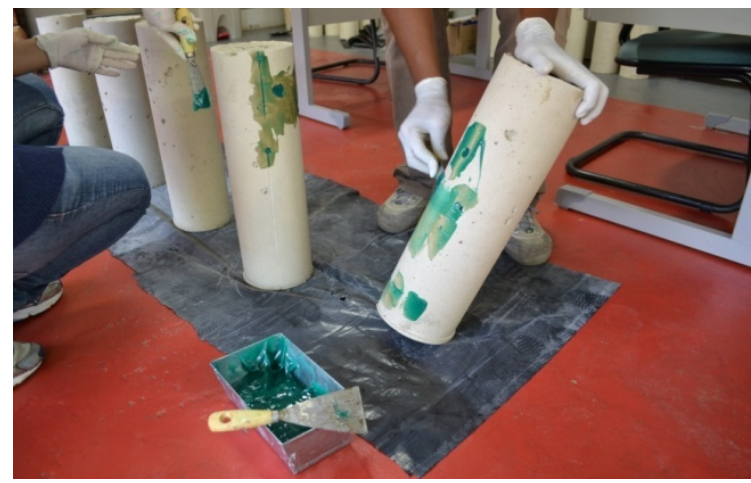

Figure 5. Plastering of the specimens

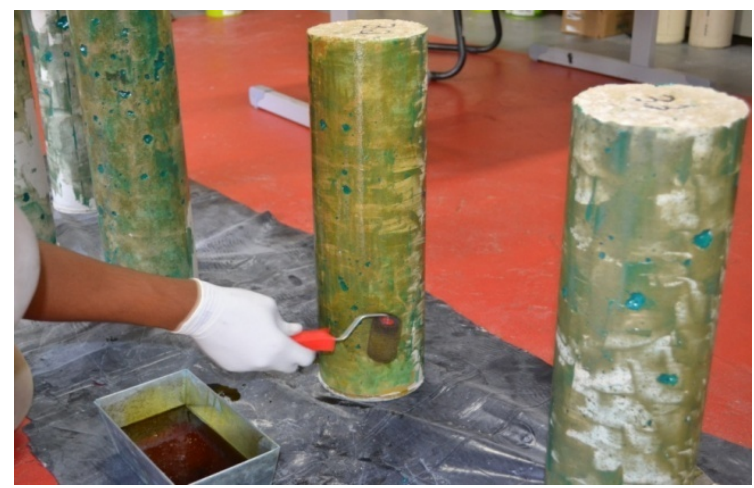

Figure 6. Priming

\section{C) Priming:}

To facilitate better adhesion condition of impregnation of concrete is also made with a primer-based epoxy (Figure 6). Note that the viscosity of the material allows for easy application with foam roller and should be taken at least two hours before the application of saturating.

D) Bonding the fibers (Figures 7 to 9):

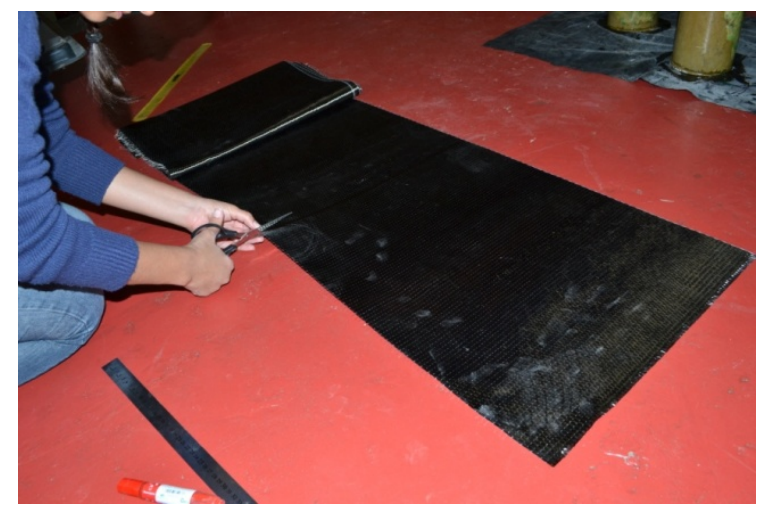

Figure 7. Cut plaid carbon fiber

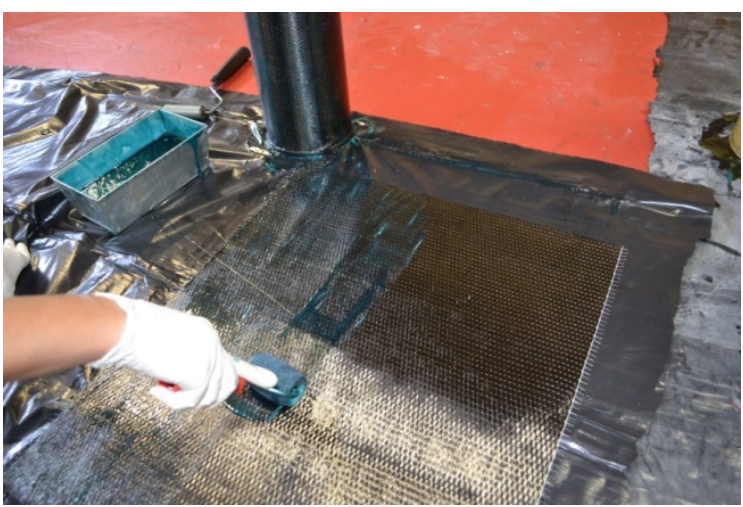

Figure 8. Application of saturating

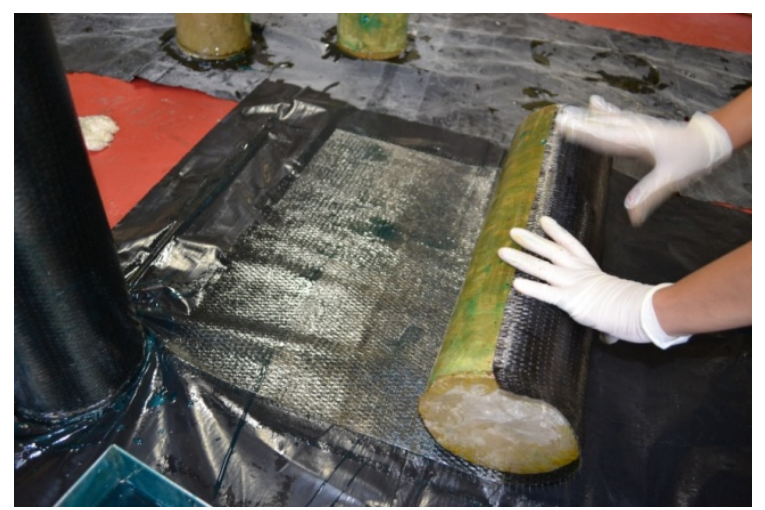

Figure 9. Application of fiber

E) Finishing (Figure 10):

28 days after the molding, the concrete specimens were systematically tested in axial compression test according to the Brazilian standard ABNT NBR 5739 [20] "Concrete-Compression tests of cylindrical specimen", keeping the recommended speed of implementation load of $0.45 \mathrm{MPa} / \mathrm{s}$. 
The evaluation of the use of the carbon fibers composites as reinforcement in each type of manufactured concrete was performed by analysis of variance (ANOVA), Kruskal -Wallis test (nonparametric) and multiple comparison test between ranks from Student- Newman-Keuls, with BioEstat ${ }^{\circledR}$ software, version 5.0. The significance level $(\alpha)$ set for ANOVA was 5\%, and the null hypothesis $\left(H_{0}\right)$ was the stipulated equivalence between averages, implying the non-equivalence of averages for the alternative hypothesis $\left(H_{I}\right)$. P-value of the Kruskal-Wallis test below the significance level implies rejecting $H_{0}$, accepting it otherwise.

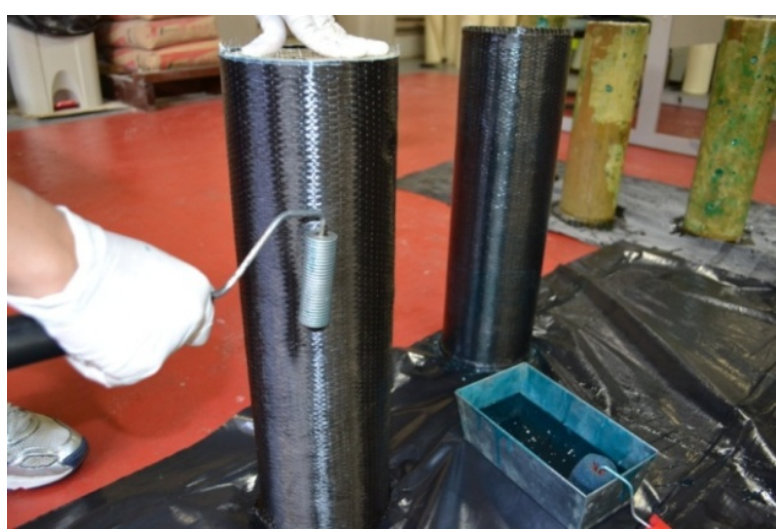

Figure 10. Finished with spiral roller

\section{Results and Discussions}

Tables 1 and 2 show the results of the compressive strength values of the specimens from the concrete made with the three distinct resistance and with and without the use of carbon fibers composite.

Table 1. Compressive strength of tested specimens without reinforcement

\begin{tabular}{cccc}
\hline Specimen & CP 1 & CP 2 & CP 3 \\
\hline Low Strength $(\mathrm{MPa})$ & 15.4 & 14.0 & 14,0 \\
Mean Strength $(\mathrm{MPa})$ & 23.1 & 26.4 & 23,6 \\
High Strength $(\mathrm{MPa})$ & 41.3 & 42.3 & 41.5
\end{tabular}

Table 2. Compressive strength of tested specimens with reinforcement

\begin{tabular}{cccc}
\hline Specimen & CP 1 & CP 2 & CP 3 \\
\hline Low Strength $(\mathrm{MPa})$ & 43.20 & 50.20 & 41.80 \\
Mean Strength $(\mathrm{MPa})$ & 42.80 & 41.80 & 41.50 \\
High Strength $(\mathrm{MPa})$ & 50.30 & 51.90 & 51.00 \\
\hline
\end{tabular}

From Tables 1 and 2 it appears that the average values of strength were increased in all three types of concrete investigated by the inclusion of laminated composite of carbon fibers as reinforcement. The inclusion of carbon fibers provided the concrete of low strength, efficiency factor of 258.60, and 62.10 and 2.70 for concretes of medium and high strength, respectively, evidencing be the most effective reinforcement for the concrete of low strength, justified by the lower tensile strength, which means striving responsible for bringing the specimens to failure.

The brittle behavior of concrete-composite system is noted in Figure 11, where it can be seen that the break in all specimens occurred abruptly [20, 21], preceded by characteristic popping burst of elements of carbon fiber and the concrete remained relatively intact.
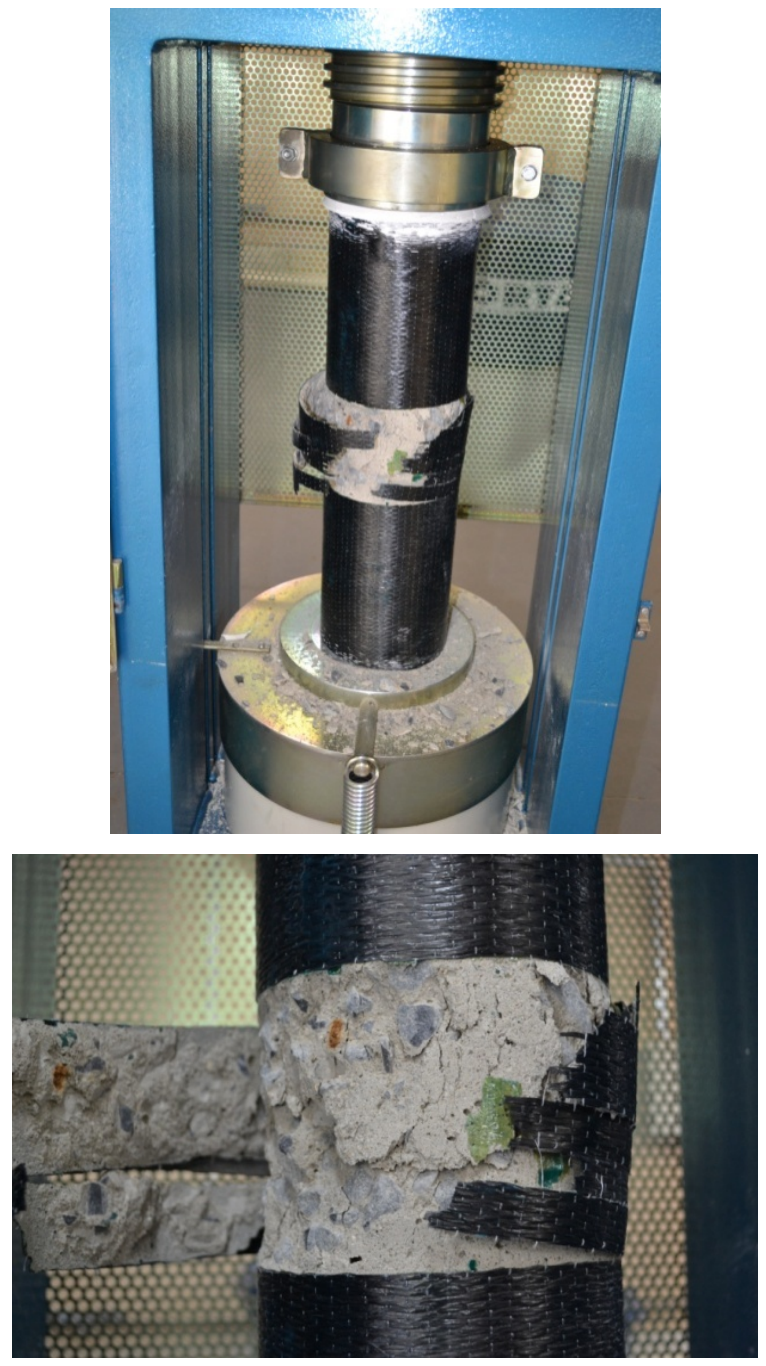

Figure 11. Detail of the breakup region of the specimen

Table 3. Results of ANOVA Kruskal-Wallis test for low strength concrete

\begin{tabular}{ccc}
\hline & Results \\
\hline H & 3.9606 & \\
GL & 1 & \\
P- value of Kruskal-Wallis & 0,0463 & \\
R1 (mean rank) & 2.000 & \\
R2 (mean rank) & 5.000 & \\
\cline { 2 - 3 } Comparasions Student-Newman-Keuls & Rank Diff. & P-value \\
Group (1 e 2) & 3.000 & 0.0495 \\
\hline & &
\end{tabular}


Table 4. Results of Kruskal-Wallis ANOVA for medium strength concrete

\begin{tabular}{ccc}
\hline & Results & \\
GL & 3.8571 & \\
P- value of Kruskal-Wallis & 1 & \\
R1 (mean rank) & 0.0495 & \\
R2 (mean rank) & 2.000 & \\
Comparasions Student-Newman-Keuls & 5.000 & \\
\cline { 2 - 3 } Group (1 e 2) & Rank Diff. & P-value \\
& 3.000 & 0.0495 \\
\hline
\end{tabular}

Table 5. Results of Kruskal-Wallis ANOVA for high strength concrete

\begin{tabular}{ccc} 
& Results \\
\hline H & 3.8571 & \\
P- value of Kruskal-Wallis & 1 & \\
R1 (mean rank) & 0.0495 & \\
R2 (mean rank) & 2.000 & \\
Comparasions Student-Newman-Keuls & Rank Diff. & P-value \\
Group (1 e 2) & 3.000 & 0.0495 \\
\hline
\end{tabular}

Tables 3 to 5 show the results of ANOVA test for the compression strength values for the three types of concrete produced on the basis of whether or not the composite reinforcement, GL being the degrees of freedom and R1 and R2 mean ranks and related to the concrete without using laminated composite and carbon fibers.

Tables 2 to 5 , the $P$-values were less than 0.05 , evidencing the samples evaluated here, the significance of inclusion of the laminate carbon fibers composite in the three kinds of concrete investigated.

\section{Conclusions}

The application of the laminated carbon fiber composites showed a simple and rapid technique for performing structural reinforcement.

From the results obtained, it was found that the gain in strength caused by the application of the composite material in the three classes of resistance. However, it was observed that the efficiency factor of the reinforcement with carbon fibers is considerably higher in the lowest specific strength. As you increase the resistance of reinforced concrete, the percentage performance gain caused by the applied system is reduced $(258.6 \%$ for low strength and $22.7 \%$ for high performance).

Whereas many of the works that are undergoing structural reinforcement are older works whose concrete has lower resistance, enhanced through the composite carbon fiber proves ideal. Therefore, the compressive strength of the concrete can be increased by a simple and rapid technique, without increasing the weight of the structure itself and the sections of the pillars.

Another factor concerns the durability. Some of the earliest works show a porous concrete, thus very susceptible to the action of aggressive environmental agents. As the application of carbon fibers makes use of epoxy resin, forms a waterproof layer along the reinforced section, thus improving its impermeability which translates into increased their lifespan.

\section{REFERENCES}

[1] Meier, U. Strengthening of structures using carbon fibre/epoxy composites. Construction and Building Materials, v. 9 , n. 6 , p. 341-351, 1995.

[2] T. Uomoto. Use of fiber-reinforced polymer composites as reinforcing material for concrete. J Mater Civil Eng, 14 (3), pp. 191-209, 2002.

[3] Stone D, Koenigsfeld D, Myers J, Nanni A. Durability of GFRP rods, laminates and sandwich panels subjected to various environmental conditioning. In: Proceeding of 2 nd international conference on durability of fiber reinforced polymer (FRP) composites for construction, Montreal, Canada, p. 213-24, 2002.

[4] G. Nkurunziza, P. Cousin, R. Masmoudi, B. Benmokrane. Effect of sustained tensile stress and temperature on GFRP composite bars properties. 1: preliminary experiment in deionised water and alkaline solution. Int $\mathbf{J}$ Mater Product Technol, 19 (1-2), pp. 15-27, 2003.

[5] Monti M, Renzelli, M, Luciani P. FRP adhesion in uncracked and cracked concrete zones. In: Proc. of 6th international symposium on FRP reinforcement for concrete structures. Singapore: World Scientific Publications. p. 183-92, 2003.

[6] R. Sen. Durability of advanced composites in a marine environment. Int J Mater Product Technol, 19 (1-2), pp. 118-129, 2003.

[7] F. Micelli, A. Nanni, Durability of FRP rods for concrete structures, Construction and Building Materials, 18 (7), pp. 491-503, 2004.

[8] Barros, J. A. O.; Ferreira, D. R. S. M.; Fortes, A. S.; Dias S. J. E. Assessing the effectiveness of embedding CFRP laminates in the near surface for structural strengthening. Guimarães, Potugal, Departamento de engenharia Civil da Universidade do Minho, 2005.

[9] Lu, X. Z.; Ye, L. P; Teng, J. G.; Jiang, J. J. Meso-scale finite element model for FRP plates/sheets bonded to concrete. Engineering Structures; 27(4): 564-75, 2005.

[10] Ferrier, E.; Bigaud, D.; Hamelin, P.; Bizindavyi, L.; Neale, K. W. Fatigue of CFRPs externally bonded to concrete. Materials and Structures, volume 38, n. p. 39-46, 2005.

[11] Meneghetti, L. C.; Garcez, M. R.; Silva Filho, L. C. P.; Gastal, F. P. S. L. Fatigue life regression model of reinforced concrete beams strengthened with FRP. Magazine of Concrete Research, v. 63. p. 539-549, 2011.

[12] Carmona F. A., Patologia das estruturas de concreto (Apostila). 2002.

[13] Falcão Bauer, L. A., Materiais de Construção. São Paulo: Pini, 2005. 
[14] Machado, A. P. Reforço de estruturas de concreto armado com fibras de carbono. São Paulo: Pini, 2002.

[15] Machado, A. P. Manual de reforço das estruturas de concreto armado com fibras de carbono. São Paulo: Viapol, 2010.

[16] Machado, A. P. Manual prático de dimensionamento. São Paulo: BASF. 2006.

[17] Menezes, A. M. Metodologia de pesquisa científica aplicada à Construção Civil. Belo Horizonte: FUMEC - FEA. $1^{\text {a }}$ Edição. 2010.

[18] Takeuti, A. R. Comportamento resistente imediato e ao longo do tempo de pilares reforçados por meio de encamisamento com concreto de alto desempenho. Tese Doutorado. Escola de Engenharia de São Carlos da Universidade de São Paulo. 2003.

[19] Associação Brasileira de Normas Técnicas. ABNT NBR 5738. Concreto - Procedimento para moldagem e cura de corpos-de-prova. Rio de Janeiro, 2003.

[20] Associação Brasileira de Normas Técnicas. ABNT NBR 5739 - Concreto - Ensaios de compressão de corpos-de-prova cilíndricos. Rio de Janeiro, 2007.

[21] American Concrete Institute. ACI-440. Guide for the design and construction of concrete reinforced with FRP bars. 2000. 